\title{
Some results relevant to the discussion of a possible link between cosmic rays and the Earth's climate
}

\author{
Gerhard Wagner, David M. Livingstone, Jozef Masarik, ${ }^{1}$ Raimund Muscheler, and Jürg \\ Beer \\ Department of Environmental Physics, Swiss Federal Institute of Environmental Science and Technology (EAWAG), \\ Dübendorf, Switzerland
}

\begin{abstract}
Based on a 16-year observation period (1980-1995), it was claimed recently that Earth's climate was linked to variations in the flux of cosmic rays penetrating into the atmosphere via their postulated effect on global cloud cover. Data from three independent studies yield information relevant to the ongoing discussion of the likelihood of the existence of such a link. (1) Model calculations show that the relative change in the ion production rate from a solar maximum to a solar minimum is of the same order as, or even greater than, the corresponding change in global cloud cover. (2) However, the smoothed combined flux of ${ }^{10} \mathrm{Be}$ and ${ }^{36} \mathrm{Cl}$ at Summit, Greenland, from 20-60 kyr B.P. (proportional to the geomagnetically modulated cosmic ray flux) is unrelated to the corresponding $\delta^{18} \mathrm{O}$ and $\mathrm{CH}_{4}$ data (interpreted as supraregional climate proxies). (3) Furthermore, although a comparison of the incoming neutron flux with cloud cover in Switzerland over the last 5 decades shows a significant correlation at times during the 1980s and 1990s, this does not occur during the rest of the period.
\end{abstract}

\section{Introduction}

The relative importance of the Sun as a factor involved in climate change is an important topic of current scientific debate. Eddy [1976] suggested that a decrease in solar activity during the Maunder Minimum (1645-1715 A.D.) may have been the reason for the cooler climate prevailing at that time. During the last decade, there has been increasing evidence that changes in climate may be closely related to changes in solar activity [Damon and Jirikowic, 1992; Lean et al., 1995; Lassen and Friis-Christensen, 1995; Magny, 1993; Stuiver et al., 1995, 1997; Reid, 1997; Svensmark and FriisChristensen, 1997; Svensmark, 1998; Tett et al., 1999]. However, the total solar irradiance, which has been measured by satellite since 1978 , changes only by $\sim 1 \%$ (on timescales exceeding 1 year) between the maximum and the minimum of the solar cycle [Willson, 1997; Beer et al., 2000]. Larger irradiance changes over longer timescales are possible, but, as yet, no measurements exist that would support such a hypothesis. There is therefore no generally accepted model providing a quantitative explanation of how the Sun (via total solar irradiance changes) might trigger climate changes, such as the transitions to and from the Little Ice Age, which are of the order of $1{ }^{\circ}-2^{\circ} \mathrm{C}$ [Mann et al., 1998; Pfister, 1999].

However, it was claimed recently that the missing link in the solar-climate relationship had been found [Svensmark and Friis-Christensen, 1997]. It was suggested that changes in solar activity and geomagnetic field intensity might be triggering changes in the Earth's climate by modulating the

\footnotetext{
${ }^{1}$ Now at the Department of Nuclear Physics, Faculty of Mathematics and Physics, Comenius University, Bratislava, Slovakia.

Copyright 2001 by the American Geophysical Union

Paper number 2000JD900589.

0148-0227/01/2000JD900589\$09.00
}

galactic cosmic ray (GCR) flux penetrating into the atmosphere [Svensmark and Friis-Christensen, 1997; Svensmark, 1998]. In its original form, this hypothesis was based mainly on the argument that changes in oceanic cloud cover occurred in phase with changes in the GCR flux during a period of several years in the 1980s and 1990s. Further investigations [Marsh and Svensmark, 2000] support the earlier results, but restrict the observed correlations to the mean global low cloud cover below an altitude of $\sim 3200 \mathrm{~m}$. The studies of Svensmark and Friis-Christensen [1997] and Svensmark [1998] have generated much well-publicized controversy, not only among scientists, but also in the more popular literature [e.g., Calder, 1997]. For this reason, we refer here to the proposed empirical link between GCRs, cloud cover, and air temperature as the Svensmark link, in spite of the fact that the deterministic microphysical mechanism by which GCRs might influence cloud formation has not yet been ascertained beyond all doubt. Several such microphysical mechanisms have been proposed, however [e.g., Dickinson, 1975; Tinsley, 1996a, b, 2000]. Dickinson [1975], for instance, speculated that GCRinduced ionization near the tropopause might influence the formation of sulfate aerosol cloud condensation nuclei. In contrast, Tinsley [1996a, b, 2000] proposed a mechanism whereby GCRs modulate the ionosphere-Earth current density flow $J_{z}$ in the global electric circuit, thereby modulating rates of ice nucleation. Although both of these mechanisms may lead to similar impacts by GCRs on mid-latitude and low-latitude cloud cover because of variations in the solar wind over the solar cycle, they differ in their prediction of the effect of the terrestrial modulation of GCRs by variations in the geomagnetic dipole field. This is because $J_{z}$ responds differently to variations in the geomagnetic field than it does to variations in solar activity, whereas the production of cloud condensation nuclei by cosmic ray ionization does not. Therefore, to distinguish between the different cloud formation mechanisms, one must investigate the impact of the 


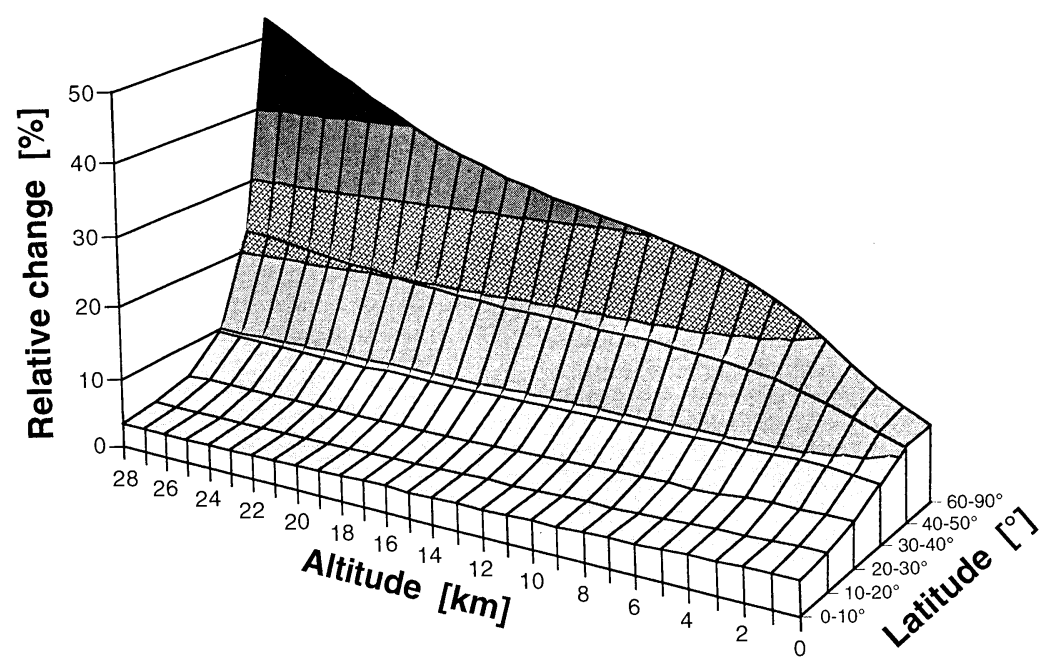

Figure 1. Relative variation in ion concentration in the Earth's atmosphere $\left(1-P_{\max } / P_{\min }\right)$ between the solar minimum $(\Phi=200 \mathrm{MeV})$ and the solar maximum $(\Phi=1000 \mathrm{MeV})$ as a function of latitude and altitude. $P_{\text {min }}$ and $P_{\max }$ denote ion production rates at the solar minimum and solar maximum, respectively; $\Phi$ is the solar modulation parameter [Masarik and Beer, 1999].

geomagnetic field on cloud formation. Assuming that cloud cover, and therefore climate, does vary with the modulated GCRs penetrating into the atmosphere, then if the Dickinson mechanism is correct, variations in GCR flux should have an influence on the climate, irrespective of whether these variations are the result of solar activity or of modulation by the geomagnetic field. According to the Tinsley mechanism, however, one would expect climate to be strongly correlated with solar activity, but not with geomagnetic field strength.

Since the validity or lack thereof of the Svensmark link has far-reaching implications for the current discussion on global climate change, we feel that all available relevant data should be scrutinized to determine whether or not they support this link. From our work on atmospheric ion production, polar ice cores, and alpine climate history, we have three such sets of data that can be examined to provide some indication of the plausibility of the Svensmark link and also, potentially, provide some help in determining the validity of the postulated cloud formation mechanisms.

\section{Results and Discussion}

1. Since clouds are important for the Earth's radiation budget [Ramanathan et al., 1989], any variation in cloud cover caused by changes in the GCR flux will affect the climate. GCRs consist of energetic particles (87\% protons, $12 \% \alpha$-particles, $1 \%$ heavier particles) [Masarik and Beer, 1999]. When they enter the Earth's atmosphere, nuclear reactions take place, yielding secondary particles that can penetrate more deeply into the atmosphere. As a consequence, ionization in the atmosphere takes place at the same altitudes at which cloud formation occurs. Thus the effects of this ionization on optical transparency, either via changes in aerosol chemistry or via an influence on the transition between different water phases, could be responsible for the observed correspondence between GCRs and cloud cover [Dickinson, 1975; Svensmark, 1998].

The physical model of Masarik and Beer [1999], which describes the propagation of GCR particles in the atmosphere, was employed to provide data on the ion production rate as a function of solar activity and geomagnetic dipole field intensity. Using a Monte Carlo code to simulate GCR interactions with the Earth's atmosphere, we calculated the ionization rates of atoms in the atmosphere caused by the primary and secondary particles of the GCR. Our calculations show that, depending on altitude and latitude, between $3 \%$ and $53 \%$ more ions are produced during the solar minimum than during the solar maximum (Figure 1). The difference between the ionization rates at the solar minimum and the solar maximum is smaller at lower latitudes than higher latitudes. Assuming a quasi-stationary equilibrium to exist between ion production and recombination processes, the application of the ion balance equation of Ermakov et al. [1997] leads to the conclusion that the relative difference in ion concentration is less than or equal to the relative difference in the production rates. The relative difference in the ionization rate between solar minimum and solar maximum is of the same magnitude as, or larger than, the observed difference in cloud cover. This relative difference decreases with decreasing altitude, and at the altitudes at which clouds are formed (about 0 to $12 \mathrm{~km}$ ), it is of the order of $3-30 \%$. However, it should be stressed here that, as admitted by Svensmark and Friis-Christensen [1997] and Marsh and Svensmark [2000], the role played by ions in the cloud formation process is still not completely understood. It is therefore not at all evident that variations in the number of ions in the atmosphere caused by variations in the GCR flux substantially affect cloud cover. Nevertheless, our calculations of the ion production rate as a function of altitude and latitude now make it possible to make quantitative comparisons of the variations in cloud cover at different altitudes and latitudes with corresponding variations in ion production. This is potentially of great importance to an examination of the Svensmark link in combination with the Dickinson mechanism, since the ion production rate in the atmosphere can now be calculated for the past (e.g., for the Maunder Minimum [Eddy, 1976]), if geomagnetic field strength and solar activity are known. 
2. The crucial point of the Svensmark link is that the change in the GCR flux has the potential to explain nearly all the mean global warming observed over the last few decades [Svensmark and Friis-Christensen, 1997; Svensmark, 1998; Marsh and Svensmark, 2000]. If the proposed causal relationship between GCR flux, cloud cover, and mean global temperature is correct, then long-term variations in the GCR flux can be expected to cause corresponding variations in the mean global temperature. Svensmark and Friis-Christensen [1997] stated that changes in the geomagnetic dipole field intensity induce corresponding changes in the GCR flux and should therefore have a significant effect on the global climate which would occur independently of solar luminosity. However, this statement is only true if the Dickinson mechanism (or some similar mechanism involving the GCR modulation of ionization) is responsible for cloud formation. If the Tinsley mechanism is responsible, however, one would expect no strong correlation to exist between geomagnetic field strength and climate. Therefore, if the Eartl's climate can be shown to have been affected by the geomagnetic dipole field via the GCR flux independently of variations in solar activity, this would yield a strong indication of the validity of both the Svensmark link and the Dickinson mechanism. In contrast, the lack of such an influence would tend to call into question the general validity of the Svensmark link if it is assumed to act through the Dickinson mechanism, but not if it is assumed to act through the Tinsley mechanism.

A very significant change in the GCR flux penetrating into the atmosphere occurred $\sim 40 \mathrm{kyr}$ ago during the so-called Laschamp event, when the geomagnetic field intensity was only $\sim 10 \%$ of its present value [Meynadier et al., 1992; Tric et al., 1992; Guyodo and Valet, 1996; Wagner et al., 2000]. If the Svensmark link and the Dickinson mechanism are valid, we would expect significant global cooling to have occurred at this time. The Greenland Ice Core Project (GRIP) ice core from Summit, Greenland, provides an ideal archive to test this inference. Measurements of the radionuclides ${ }^{10} \mathrm{Be}$ and ${ }^{36} \mathrm{Cl}$ in the GRIP core, which are proxies for the GCR flux [Masarik and Beer, 1999], are available for the last ice age [Baumgartner et al., 1997; Yiou et al., 1997]. It has been shown that, after low-pass filtering, the combined flux of ${ }^{10} \mathrm{Be}$ and ${ }^{36} \mathrm{Cl}$ reflects the GCR flux, which is modulated by the changing geomagnetic field [Baumgartner et al., 1998; Wagner et al., 2000]. Combining and low-pass filtering the ${ }^{10} \mathrm{Be}$ and ${ }^{36} \mathrm{Cl}$ fluxes reduces transport and solar activity effects, which are assumed to occur on timescales shorter than $3 \mathrm{kyr}$ [Damon and Sonett, 1991]. The $\delta^{18} \mathrm{O}$ and $\mathrm{CH}_{4}$ data can be regarded as proxies for the climate of the North Atlantic region at least [Bond et al., 1993; Dansgaard et al., 1993; Blunier et al., 1998]. It is suggested that they are controlled by the hydrological cycle at low latitudes [Chappelaz et al., 1993] and are therefore proxies for a supraregional climate. Both records are available as a function of time [Dansgaard et al., 1993; Blunier et al., 1998].

In Figure 2 the combined, low-pass-filtered flux of ${ }^{10} \mathrm{Be}$ and ${ }^{36} \mathrm{Cl}$ (reflecting the GCR flux modified by the geomagnetic field) is compared with the $\delta^{18} \mathrm{O}$ and $\mathrm{CH}_{4}$ data (reflecting the climate). If both the Svensmark link and the Dickinson mechanism are valid, the maximum of the combined flux of ${ }^{10} \mathrm{Be}$ and ${ }^{36} \mathrm{Cl}$ should be correlated with the $\delta^{18} \mathrm{O}$ data (note the inverse scale) and $\mathrm{CH}_{4}$ data. A high value of the combined flux of ${ }^{10} \mathrm{Be}$ and ${ }^{36} \mathrm{Cl}$ corresponds to a high GCR flux, which, according to the Svensmark link, should result in an increase in global cloud cover and a lower mean global temperature. This is, however, clearly not the case. During the Laschamp event (36-41.5 kyr B.P.), marked by a peak in the radionuclide data, the combined flux of ${ }^{10} \mathrm{Be}$ and ${ }^{36} \mathrm{Cl}$ is not significantly $(p$ $<0.1)$ correlated with either $\delta^{18} \mathrm{O}\left(r^{2}=0.07 \%\right)$ or $\mathrm{CH}_{4}\left(r^{2}=\right.$ $0.09 \%)$. The same applies over the entire time interval shown in Figure $2\left(r^{2}=0.3 \%\right.$ and $0.4 \%$, respectively). This suggests that the relationship between geomagnetic field, GCRs, and climate proposed by Svensmark and Friis-Christensen [1997] and Svensmark [1998] is unlikely to be valid for the period investigated here. This conclusion is strengthened by the fact that the variation in the GCR flux that occurred during the Laschamp event was substantially greater than the variations associated with the 11-year solar modulation that occurred during the 1980s and 1990s [Wagner et al., 2000; Baumgartner et al., 1998; Masarik and Beer, 1999]. Our result that the enhanced GCR flux prevailing during the Laschamp event had no significant impact on climate is inconsistent with the Svensmark link acting through the Dickinson mechanism. However, it is not inconsistent with a scenario in which the Svensmark link acts via the Tinsley mechanism.

3. The plausibility of the Svensmark link can also be investigated on a much shorter timescale using recent climate data. One weak point of the Svensmark link is that the comparison between cloud cover and neutron flux measurements on which it rests is based on a series of only 16 years of cloud cover data (1980-1995). This rather short data series is a composite of four even shorter series ( $\leq 7$ years) from different satellites, which might give rise to intercalibration problems [Kernthaler et al., 1999]. However, the existence of longer-term historical cloud cover observations allows the comparison of cloud cover and GCRs to be extended back to the beginning of the Cheltenham neutron flux data series in 1937 , albeit only on a regional basis. There are three major possible outcomes of such an extended comparison with regional cloud cover: (1) the detection of a consistent, common signal over the entire observation period would lend support to the Svensmark link; (2) the failure to detect any such signal during the entire observation period would not lend support to the Svensmark link, but would also not invalidate it because of the regional nature of the cloud cover data; (3) the detection of a common signal during the period on which the Svensmark link is based (1980-1995), but not previous to this period, may indicate that any correlation between cloud cover and incident neutron flux is confined to the last 2 decades, thus calling into question the general validity of the link.

In Figure 3 the measured neutron flux since 1937 is compared with corresponding observations of the mean cloud cover over the Swiss Plateau. Figure 3a illustrates the neutron flux registered at Cheltenham (United Kingdom), Climax (United States), and Jungfraujoch (Switzerland). The neutron fluxes registered in various parts of the world are similar [Svensmark and Friis-Christensen, 1997], so the concatenated Cheltenham and Climax curves can be considered to be representative of global values from 1937 up to the present. The similarity of the Jungfraujoch and Climax curves shows that fluctuations in the neutron flux incident on the Swiss Alps do not differ substantially from global values.

Time series of historical cloud cover observations covering much of the 20th century are available from various meteorological stations in Switzerland. On the Swiss Plateau 


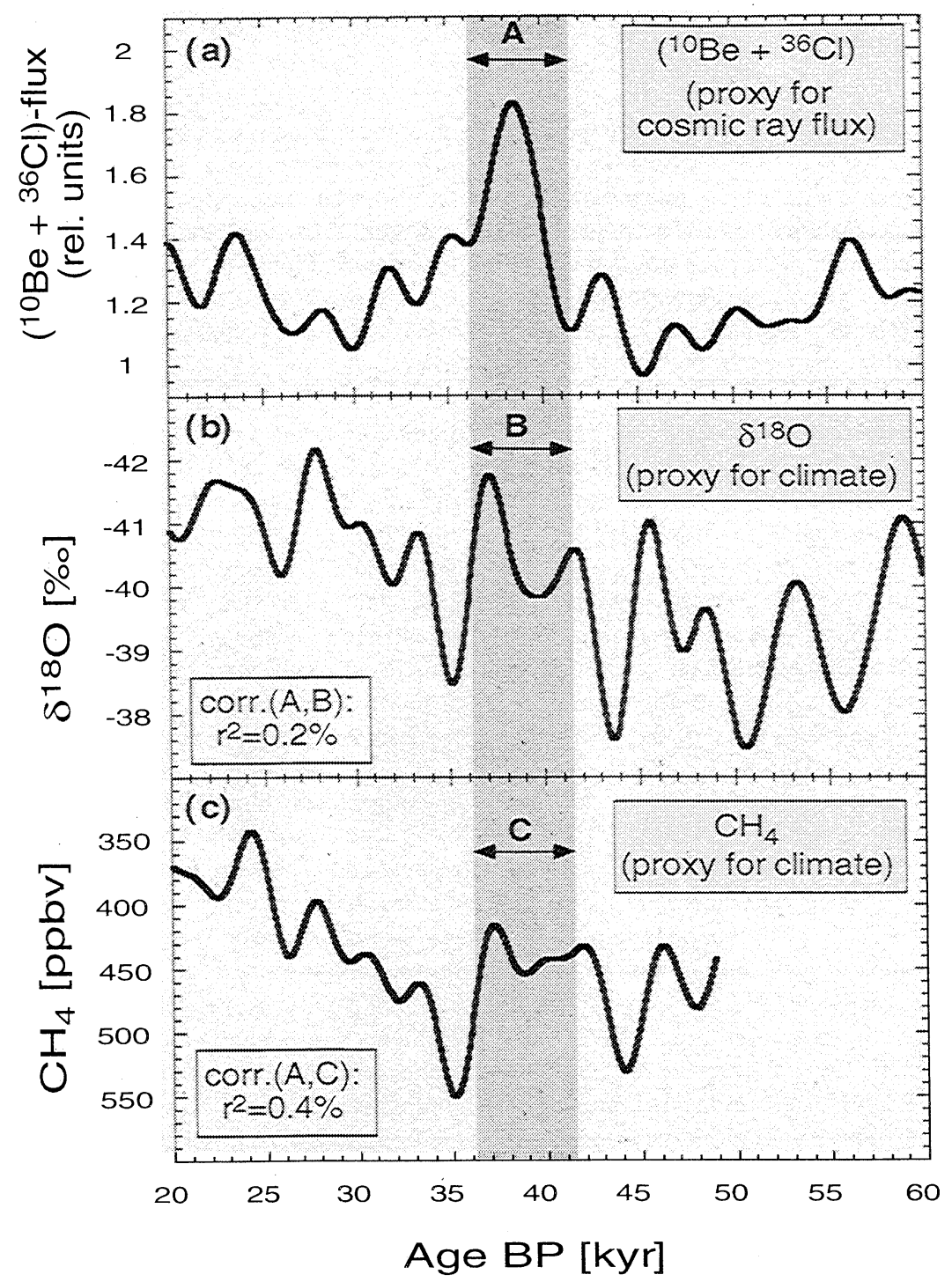

Figure 2. (a) Normalized, combined flux of ${ }^{10} \mathrm{Be}$ and ${ }^{36} \mathrm{Cl}$ after low-pass filtering (cutoff frequency $=1 / 3000 \mathrm{yr}^{-1}$ ) [Baumgartner et al., 1998; Wagner et al., 2000]. The peak at $38 \mathrm{kyr}$ B.P. corresponds to a minimum in the Earth's geomagnetic field intensity, the so-called Laschamp event (36-41.5 kyr B.P.). (b) The $\delta^{18} \mathrm{O}$ data from the Greenland Ice Core Project (GRIP) ice core after low-pass filtering (cutoff frequency $=1 / 3000 \mathrm{yr}^{-1}$ ). These data can be interpreted as a climate proxy for the North Atlantic region at least [Bond et al., 1993; Dansgaard et al., 1993; Blunier et al., 1998]. The proportion of variance shared between the combined flux of ${ }^{10} \mathrm{Be}$ and ${ }^{36} \mathrm{Cl}$ and the $\delta^{18} \mathrm{O}$ data during the Laschamp event is essentially zero. The proportion of shared variance over the period 20-60 kyr B.P. is also essentially zero. (c) $\mathrm{CH}_{4}$ data from the GRIP ice core after low-pass filtering (cutoff frequency $=1 / 3000 \mathrm{yr}^{-1}$ ). These data can also be interpreted as a climate proxy. Again, the proportion of variance shared between the combined flux of ${ }^{10} \mathrm{Be}$ and ${ }^{36} \mathrm{Cl}$ and the $\mathrm{CH}_{4}$ data during the Laschamp event is essentially zero. The proportion of shared variance over the period 20-50 kyr B.P. is also essentially zero. The $\delta^{18} \mathrm{O}$ and $\mathrm{CH}_{4}$ data are well correlated $\left(r^{2}=0.61\right)$.

(300-600 m above sea level (asl)), the comparatively lowlying part of Switzerland north of the Alps, air temperatures show a very high degree of spatial coherence, so that a mean time series based on data from the four stations BaselBinningen (BS), Neuchâtel (NE), Zürich-MZA (ZH), and BernLiebefeld (BE), can be considered to be representative of the whole Swiss Plateau [Livingstone and Lotter, 1998]. The Swiss Plateau also shows a high degree of spatial coherence with respect to cloud cover, and cloud cover data from the same four stations are highly correlated: a comparison of each monthly mean anomaly cloud cover series individually with the mean of the other three anomaly series (1901-1998, $\mathrm{n}=$ 1176) yielded correlations significant at the $\mathrm{p}<0.0001$ level with shared variances $\left(r^{2}\right)$ of $72 \%(\mathrm{BS}), 75 \%(\mathrm{NE}), 80 \%(\mathrm{ZH})$ and $81 \%(\mathrm{BE})$. Thus the mean cloud cover time series of all four stations, hereafter referred to as series $\mathrm{C} 1$ (Figure 3b), can be considered to be generally representative of the mean cloud cover over the Swiss Plateau, integrated over all altitudes. Simultaneous, independent measurements of relative sunshine duration (RS1, Figure 3b) exhibit a temporal structure similar to that of series $\mathrm{Cl}$, confirming the reliability of the cloud cover observations (the monthly anomalies of RS1 and C1 
over the period 1901-1998 show 79\% shared variance). An indication that the Swiss cloud cover data are of at least European significance is given by the fact that the monthly anomalies of series $\mathrm{C} 1$ are significantly inversely correlated ( $p$ $<0.0001$ ) with the monthly anomalies of air temperature series measured several hundred kilometers from the Swiss Plateau in the western European North Atlantic coastal region, including Manley's [1974] central England air temperature series as extended by Parker et al. [1992] (1901-1990; $n=$ $\left.1080, r^{2}=18 \%\right)$ and the Netherlands De Bilt series (1901$1990 ; n=1080, r^{2}=11 \%$ ). In addition, the fact that the advances and retreats of Swiss Alpine glaciers are known to reflect the same climate changes that are recorded in various different climate archives (e.g., polar ice cores, tree rings, North American alpine glaciers) distributed throughout the Northern Hemisphere [Hormes et al., 1998; Röthlisberger et al., 1980; Denton and Karlén, 1973] points to the supraregional significance of the Swiss climate data.

Comparison of Figures $3 \mathrm{a}$ and $3 \mathrm{~b}$ reveals that, over the period on which the Svensmark correlation is based (the shaded area in Figure 3), a broad structural similarity does indeed exist between the neutron flux data and cloud cover over the Swiss Plateau. The neutron flux maximum in 19861987 and minimum in 1990-1991, for instance, coincide well with corresponding extrema in series $\mathrm{Cl}$, and a running correlation between monthly anomalies of the concatenated Cheltenham/Climax neutron flux data and series $\mathrm{Cl}$ is significant at the $p<0.05$ or even the $p<0.01$ level during a large part of the 1980-1995 period (Figure 3c). At first sight this would appear to lend regional support to the global Svensmark link. However, there is no convincing evidence relating series $\mathrm{Cl}$ to the neutron flux data previous to 1979 The third of the three outcomes listed above therefore applies. The fact that global satellite cloud cover data and regional cloud cover over the Swiss Plateau both correlate well with the incident neutron flux during the last 2 decades, coupled with the lack of such a correlation in the case of the Swiss data prior to 1979 , suggests the possibility that the correlation in the case of the global cloud cover data may also be confined to the last 2 decades.

A more detailed analysis revealed considerable seasonal variability in the degree of similarity between the Climax neutron flux data and series C1 in 1980-1995, with by far the strongest relationship being apparent in winter (1980-1995; $\left.n=16, r^{2}=60 \%, p<0.001\right)$. In winter, frequent temperature inversions over the Swiss Plateau result in persistent stratus with a mean thickness of 200-500 $\mathrm{m}$ and an upper limit of 800$1400 \mathrm{~m}$ that essentially decouples the Swiss Plateau from processes occurring at higher elevations [Beniston and Rebetez, 1996]. The strong relationship found between the neutron flux data and winter cloud cover over the Swiss Plateau is therefore consistent (on a regional scale) with the fact that the same neutron flux data are qualitatively wellcorrelated with optically thick low-altitude cioud cover $(<3.2$

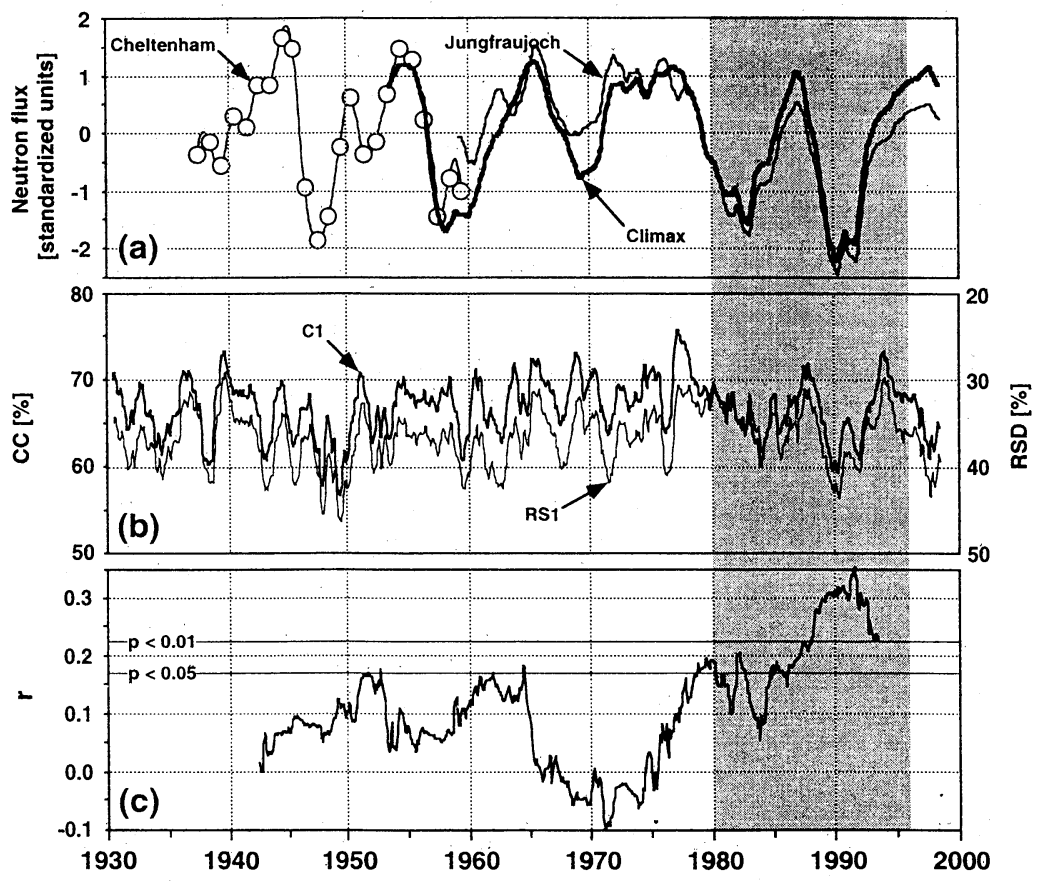

Figure 3. (a) Neutron flux measured at Cheltenham, United Kingdom (spline-interpolated annual means, $1937-$ 1959); Climax, Colorado, United States (12-month running means, 1953-1998); and Jungfraujoch, Switzerland (12-month running means, 1958-1998). The data were standardized by removing the mean and dividing by the standard deviation. (b) Mean cloud cover (C1) and relative sunshine duration (RS1) on the Swiss Plateau: mean of measurements from Basel-Binningen (316 m above sea level (asl)), Neuchâtel (487 m asl), Zürich-MZA (556 m asl) and Bern-Liebefeld (570 $\mathrm{m}$ asl) (12-month running means). (c) Running correlation coefficient $r$ between monthly anomalies of the neutron flux at Cheltenham and Climax and of the mean cloud cover (C1) on the Swiss Plateau (11-year sliding data window, 132 monthly anomalies; the $p<0.01$ and $p<0.05$ significance levels are shown). The time period on which the Svensmark [1998] correlation is based is shaded. Note that an inverse scale has been used for RS1 to facilitate comparison. 
$\mathrm{km}$ ), but not with middle- or high-altitude cloud cover, on the global scale [Marsh and Svensmark, 2000]. However, the lack of a correlation between GCRs and middle- and high-altitude global cloud cover also implies that the mechanism by which GCRs might influence the climate is unlikely to be one involving the formation of cloud condensation nuclei by ionization due to GCRs, as this, regardless of whether it occurs via the nucleation of water droplets or via sulfate aerosols, would be expected to have its greatest relative effect near the tropopause [Roberts and Olson, 1973; Dickinson, 1975]. The Tinsley mechanism, however, is not inconsistent with a scenario in which the primary climatically relevant influence of GCRs is on low cloud cover. Given the potential importance of the effect of GCR-related variations in $J_{z}$ on storm tracks and winter cyclone intensity, especially over the North Atlantic [Tinsley, 2000], and the importance of such large-scale climatic processes over the North Atlantic in winter for the climate of western Europe, e.g., via the North Atlantic Oscillation [van Loon and Rogers, 1978; Hurrell, 1995, 1996; Hurrell and van Loon, 1997], then a correlation between GCRs and winter stratus over the Swiss Plateau provides some evidence for the relative plausibility of the Tinsley mechanism compared with any of the mechanisms that involve the production of cloud condensation nuclei near the tropopause. However, the fact that the correlation in the case of the Swiss data is limited to the same time period as that of the Svensmark correlation does not allow a general statement to be made that would clearly support either the general existence of the empirical Svensmark link or any mechanism that might account for it.

\section{Conclusions}

The investigations described here are intended as a contribution to the current debate on the link between GCRs and Earth's climate. Our calculations suggest that the relative increase in the ionization rate from a solar maximum to a solar minimum is of the order of, or even larger than, the corresponding increase in cloud cover observed by Svensmark and Friis-Christensen [1997] and Svensmark [1998]. This may support the Svensmark link. However, neither the measurements of cosmogenic radionuclides, $\delta^{18} \mathrm{O}$, and $\mathrm{CH}_{4}$ in the GRIP ice core during the Laschamp event nor modern observations of cloud cover over Switzerland support the general validity of the Svensmark link. We therefore believe that the qualitative and quantitative role of the Sun in forcing the cliniate is still an open question.

Acknowledgments. We wish to thank the EAWAG laboratory crew and the accelerator crew of the PSI/ETH AMS facility for their laboratory work and valuable discussions. We also thank A. Dällenbach and his colleagues for providing us with the GRIP $\mathrm{CH}_{4}$ data, E. Flückiger for the Jungfraujoch neutron data, and the Swiss Meteorological Institute for the meteorological data. This work is a contribution (1) to the Greenland Ice Core Project (GRIP), organized by the European Science Foundation and supported by the Swiss National Science Foundation (grant 20-49347.96), and (2) to the European Union project REFLECT (contract ENV4-CT97-0453), supported by the Swiss Federal Office of Education and Science (grant 97.0344).

\section{References}

Baumgartner, S., J. Beer, B. Dittrich-Hannen, H.-A. Synal, P. W. Kubik, C. U. Hammer, and S. J. Johnsen, Chlorine 36 fallout in the Summit Greenland Ice Core Project ice core, J. Geophys. Res., 102, 26,65926,662, 1997.
Baumgartner, S., J. Beer, J. Masarik, G. Wagner, L. Meynadier, and H.A. Synal, Geomagnetic modulation of the ${ }^{36} \mathrm{Cl}$ flux in the Summit GRIP ice core, Science, 279, 1330-1332, 1998.

Beer, J., W. Mende, and R. Stellmacher, The role of the sur in climate forcing, Quat. Sci. Rev. 19, 403-415, 2000.

Beniston, M., and M. Rcbetez, Regional behaviour of minimum temperatures in Switzerland for the period 1979-1993, Theor. Appl. Climatol., 53, 231-243, 1996.

Blunier, T., et al., Asynchrony of Antarctic and Greenland climate change during the Last Glacial, Naiure, 394, 739-743, 1998.

Bond, G., W. S. Broecker, S. J. Johnsen, J. McManus, L. Labeyrie, J. Jouzel, and G. Bonani, Correlations between climate records from North Atlantic sediments and Greenland ice, Nature, 365, 143-147, 1993.

Calder, N., The Manic Sun., Pilkington, London, 1997.

Chappellaz, J., T. Blunier, D. Raynaud, J. M. Barnola, J. Schwander, and B. Stauffer, Synchronous changes in atmospheric $\mathrm{CH}_{4}$ and Greenland climate between 40 and $8 \mathrm{kyr}$ BP, Nature, 366, 443-445, 1993.

Damon, P. E., and J. L. Jirikowic, Solar forcing of global change? in Radiocarbon After Four Decades: An Interdisciplinary Perspective, edited by R.E. Taylor, A. Long, and R. S. Kra, pp. 117-129, Springer-Verlag, New York, 1992.

Damon, P. E., and C. P. Sonett, Solar and terrestrial components of the atmospheric ${ }^{14} \mathrm{C}$ variation spectrum, in The Sun in Time, edited by $\mathrm{C}$. P. Sonett, M. S. Giampapa, and M. S. Matthews, pp. 360-388, Univ. of Arizona Press, Tucson, 1991.

Dansgaard, W., et al., Evidence for general instability of past climate from a 250-kyr ice-core record, Nature, 364, 218-220, 1993.

Denton, G. H., and W. Karlén, Holocene variations - Their pattern and possible cause, Quat. Res., 3, 155-205, 1973.

Dickinson, R. E., Solar variability and the lower atmosphere, Bull. Am. Meteorol. Soc., 56, 1240-1248, 1975.

Eddy, J. A., The Maunder minimum, Science, 192, 1189-1202, 1976.

Ermakov, V. I., G. A. Bazilevskaya, P. E. Pokrevsky, and Y. I. Stozhkov, Ion balance equation in the atmosphere, J. Geophys. Res., 102, 23,413-23,419, 1997.

Guyodo, Y., and J.-P. Valet, Relative variations in geomagnetic intensity from sedimentary records: The past 200 thousand years, Earth Planet. Sci. Lett., 143, 23-26, 1996.

Hormes, A., C. Schlüchter, and T. F. Stocker, Minimal extension phases of Unteraarglacier (Swiss alps) during the Holocene based on C-14 analysis of wood, Radiocarbon, 40, 809-817, 1998.

Hurrell, J. W., Decadal trends in the North Atlantic Oscillation: Regional temperatures and precipitation, Science, 269, 676-679, 1995.

Hurrell, J. W., Influence of variations in extratropical wintertime teleconnections on Northern Hemisphere temperatures, Geophys. Res. Lett., 23, 665-668, 1996.

Hurrell, J. W., and H. van Loon, Decadal variations in climate associated with the North Atlantic Oscillation, Clim. Change, 36, 301326, 1997.

Kernthaler, S. C., R. Tourni, and J. D. Haigh, Some doubts concerning a link between cosmic ray fluxes and global cloudiness, Geophys. Res. Lett., 26, 863-865, 1999.

Lassen, K., and E. Friis-Christensen, Variability of the solar cycle length during the past five centuries and the apparent association with terrestrial climate, J. Atmos. Terr. Phys., 57, 835-845, 1995.

Lean, J., J. Beer, and R. Bradley, Reconstruction of solar irradiance since 1610: Implications for climate change, Geophys. Res. Lett., 22, 3195-3198, 1995.

Livingstone, D. M., and A. F. Lotter, The relationship between air and water temperatures in lakes of the Swiss Plateau: A case study with palæolimnological implications, J. Paleolimnol., 19, 181-198, 1998.

Magny, M., Solar influences on Holocene climatic changes illustrated by correlations between past lake level fluctuations and the atmospheric C-14 record, Quat. Res., 40, 1-9, 1993.

Manley, G., Central England temperatures: Monthly means 1659 to 1973, Q. J. R. Meteorol. Soc., 100, 389-405, 1974.

Mann, M. E., R. S. Bradley, and M. K. Hughes, Global-scale temperature patterns and climate forcing over the past six centuries, Nature, 392, 779-787, 1998.

Marsh, N., and H. Svensmark, cosmic rays, clouds, and climate, Space Sci. Rev., 94, 215-230, 2000.

Masarik, J., and J. Beer, Simulation of particle fluxes and cosmogenic nuclide production in Earth's atmosphere, J. Geophys. Res., 104, 12,099-12,113, 1999. 
Meynadier, L., J.-P. Valet, R. Weeks, N. J. Shackleton, and V. L. Hagee, Relative geomagnetic intensity of the field during the last 140 ka, Earth Planet. Sci. Lett., 114, 39-57, 1992.

Parker, D. E., T. P. Legg, and C. K. Folland, A new daily central England temperature series, 1772-1991, Int. J. Climatol., 12, 317342, 1992

Pfister, C., Wetternachhersage: 500 Jahre Klimavariationen und Naturkatastrophen, Verlag Paul Haupt, Berne, 1999.

Ramanathan, V., R. D. Cess, E. F. Harrison, P. Minnis, B. R. Barkstrom, E. Ahmad, and D. Hartmann, Cloud-radiative forcing and climate: Results from the Earth Radiation Budget Experiment, Science, 243, 57-63, 1989.

Reid, G. C., Solar forcing of global climate since the mid-17th century, Clim. Change, 37, 391-405, 1997.

Roberts, W. O., and R. H. Olson, Geomagnetic storms and wintertime $300 \mathrm{mb}$ trough development in the North Pacific-North America area, J. Atmos. Sci., 30, 135-140, 1973.

Röthlisberger, F., P. Haas, H. Holzhauser, W. Keller, W. Bircher, and F. Renner, Holocene climatic fluctuations - Radiocarbon dating of fossil soils and woods from moraines and glaciers in the Alps, Geogr. Helv., 35, 21-52, 1980.

Stuiver, M., P. M. Grootes, and T. F. Braziunas, The GISP2 $\delta^{18} \mathrm{O}$ climate record of the past 16,500 years and the role of the Sun, ocean and volcanoes, Quat. Res., 44, 341-354, 1995.

Stuiver, M., T. F. Braziunas, P. M. Grootes, and G. A. Zielinski, Is there evidence for solar forcing of climate in the GISP2 oxygen isotope record? Quat. Res., 48, 259-266, 1997.

Svensmark, H., Influence of cosmic rays on Earth's climate, Phys. Rev. Lett., 81, 5027-5030, 1998.

Svensmark, H., and E. Friis-Christensen, Variation of cosmic ray flux and global cloud coverage - A missing link in solar-climate relationships, J. Atmos. Sol. Terr. Phys. 59, 1225-1232, 1997.

Tett, S. F. B., P. A. Stott, M. R. Allen, W. J. Ingram, and J. F. B. Mitchell, Causes of twentieth-century temperature change near the Earth's surface, Nature, 399, 569-571, 1999.

Tinsley, B. A., Solar wind modulation of the global electric circuit and apparent effects on cloud microphysics, latent heat release, and tropospheric dynamics, J. Geomagn. Geoelectr., 48, 165-275, 1996a. Tinsley, B. A., Correlations of atmospheric dynamics with solar wind induced air-earth current density into cloud tops, J. Geophys. Res., 101, 29,701-29,714, 1996b.

Tinsley, B. A., Influence of solar wind on the global electric circuit, and inferred effects on cloud microphysics, temperature, and dynamics in the troposphere, Space Sci. Rev., 94, 231-258, 2000

Tric, E., J.-P. Valet, P. Tucholka, M. Paterne, L. Labeyrie, F. Guichard, L. Tauxe, and M. Fontugne, Paleointensity of the geomagnetic field during the last 80,000 years, J. Geophys. Res., 97, 9337-9351, 1992.

van Loon, H., and J. C. Rogers, The seesaw in winter temperatures between Greenland and Northern Europe, I, General description, Mon. Weather. Rev., 106, 296-310, 1978.

Wagner, G., J. Masarik, J. Beer, S. Baumgartner, D. Imboden, P. W. Kubik, H.-A. Synal, and M. Suter, Reconstruction of the geomagnetic field between 20 and $60 \mathrm{ka}$ B.P. by the cosmogenic radionuclides in the GRIP ice core, Nucl. Instrum. Methods Phys. Res., Sect. B, 172, 597-604, 2000.

Willson, R. C., Total solar irradiance trend during solar cycles 21 and 22, Science, 277, 1963-1965, 1997.

Yiou, F., et al., Beryllium 10 in the Greenland Ice Core Project ice core at Summit, Greenland, J. Geophys. Res., 102, 26,783-26,794, 1997.

J. Beer, D. M. Livingstone, R. Muscheler, G. Wagner, Department of Environmental Physics, Swiss Federal Institute of Environmental Science and Technology (EAWAG), Überlandstr. 133, CH-8600 Dübendorf, Switzerland. (beer@eawag; living@eawag.ch, muscheler@eawag.ch; gerhard.wagner@eawag.ch)

J. Masarik, Departement of Nuclear Physics, Faculty of Mathematics and Physics, Comenius University, Mlynska dolina F/2, SK-84215 Bratislava, Slovakia. (masarik@fmph.uniba.sk)

(Received March 24, 2000; revised July 31, 2000; accepted September 7, 2000.) 